\title{
Study of difference of peripheral blood lymphocytes immunophenotyping and NK cells on connective tissue disease combined with interstitial lung disease.
}

\author{
Dandan Zhang ${ }^{1 \#, ~ Y a n s h e n g ~ W a n g ~}{ }^{2 \#, ~ Y a n ~ R o n g ~}{ }^{1}$, Xiaoli Li ${ }^{1}$, Jian Xu' ${ }^{1}$, Bing Han ${ }^{1}$, Junli Wang1* \\ ${ }^{1}$ Department of Respiration, Shenzhen Hospital, Southern Medical University, Shenzhen, Guangdong, PR China \\ ${ }^{2}$ State Key Laboratory of Respiratory Disease, Guangzhou Institute of Respiratory Health, the First Affiliated Hospital \\ of Guangzhou Medical University, Guangzhou, Guangdong, PR China \\ \#These authors contribute equally
}

\begin{abstract}
Objective: To investigate the clinical value of peripheral blood lymphocytes immunophenotyping and Natural Killer cells (NK) in the judgment of the types of Connective Tissue Disease Combined with Interstitial Lung Disease (CTD-ILD).

Methods: 262 CTD-ILD patients and 50 healthy volunteers in our hospital from January 2010 to December 2015 were enrolled into the study. There were 164 patients with CTD-ILD and 98 patients with ILD. The clinical symptoms and High Resolution CT (HRCT) of all patients were observed and compared between the two groups. The serum levels of $\mathrm{CD3}^{+}, \mathrm{CD4}^{+}, \mathrm{CD8}^{+}, \mathrm{CD19}^{+}, \mathrm{CD56}^{+} \mathrm{T}$ cells were detected by flow cytometry and compared among the three groups.

Results: There were no difference of the clinical symptoms and the characteristics of HRCT between the two patients groups $(\mathrm{P}>\mathbf{0 . 0 5})$. The serum level of $\mathrm{CD3}^{+}-\mathrm{CD8}^{+} \mathrm{T}$ cells of patients in the CTD-ILD group was higher than the control group and ILD group $(\mathrm{P}<0.05)$; and the serum level of $\mathrm{CD3}^{-\mathrm{CD56}^{+} \mathrm{T} \text { cells }}$ and the ratio of $\mathrm{CD4}^{+} / \mathrm{CD8}^{+}$in the CTD-ILD group was lower than the control group and ILD group $(P<0.05)$. But there was no difference of the peripheral blood lymphocytes immunophenotyping between the ILD group and control group $(\mathbf{P}>\mathbf{0 . 0 5})$.

Conclusion: The immunophenotype of peripheral blood lymphocytes could be helpful to judge the types of connective tissue disease combined with interstitial lung disease.
\end{abstract}

Keywords: Interstitial lung disease, Connective tissue disease, Immunocyte, Immune function, Natural killer cell.

Accepted on October 9, 2017

\section{Introduction}

Interstitial Lung Disease (ILD) is generic term of lung diseases of different immune pathological process caused by multiple pathogenic factors, the onset mechanism of ILD is still unclear [1,2]. Connective Tissue Disease (CTD) belongs to injury disease of body caused by abnormal autoimmune system, of which, ILD is one of common CTD complications, which will induce failure of kidney function even death easily [3,4]. Early ILD prediction is vital of improving CTD curative effects and prognosis [5]. The onset of CTD-ILD is increasingly gradually, it has no typical clinical indications. So the diagnosis is difficult. The onset rate, pathological type and treatment effects of different CTD with ILD have relatively great differences. Therefore, it is difficult to judge whether CTD-ILD caused by infection or immune injury [6,7]. This study provides theoretical basis for clinical treatment by detecting difference changes of peripheral blood lymph cells and NK cell level of CTD-ILD patients and non-CTD ILD patients.

\section{Materials and Methods}

\section{Clinical data}

This study had enrolled 262 CTD-ILD patients and 50 healthy volunteers in internal respiratory department and IUC of State Key Laboratory of Respiratory Disease, Guangzhou Institute of Respiratory Health, the First Affiliated Hospital of Guangzhou Medical University from January 2010 to December 2015. All patients were given HRCT examination and X-ray. Complains contain cough, short of breath, chest fullness, dyspnea and so on. There were 118 male patients and 144 female patients. The age was from 21 to $76 \mathrm{y}$ old. The average age was $45.27 \pm$ $10.62 \mathrm{y}$ old. According to diagnostic criteria of MCTD diagnostic and treatment guide issued by CRA in 2011 [8], 164 patients belong to CTD-ILD type, of which, there were 72 RA, 35 SLE, 16 primary SS, 11 multiple myositis, 9 mixed connective tissue diseases, 7 JDM, 7 scleroderma, 5 overlap syndrome and 2 vasculitis. In addition, there were 98 patients as non-CTD with ILD, including 24 secondary infections, 14 
drugs, 12 GER, 48 patients without clear reasons. Furthermore, this study selected 50 healthy volunteers with health examination in outpatients department of our hospital as the control group. Comparison of general clinical data of patients in two groups, there were no statistical differences. It had comparability, $\mathrm{P}<0.05$ (Tables 1 and 2).

Table 1. Analysis of general data of admitted subjects.

\begin{tabular}{|c|c|c|c|c|c|c|c|c|}
\hline \multirow[t]{2}{*}{ Group } & \multirow{2}{*}{$\begin{array}{l}\text { Patients } \\
\text { number } \\
\text { (case) }\end{array}$} & \multirow{2}{*}{$\begin{array}{l}\text { Average age (years } \\
\text { old) }\end{array}$} & \multicolumn{2}{|c|}{ Sex (case) } & \multirow[t]{2}{*}{ Average course $(y)$} & \multirow{2}{*}{$\begin{array}{l}\text { Glucocorticoid } \\
\text { (case) }\end{array}$} & \multirow[t]{2}{*}{ use } & \multirow{2}{*}{$\begin{array}{l}\text { Respiratory } \\
\text { frequency (times/ } \\
\text { min) }\end{array}$} \\
\hline & & & Male & Female & & & & \\
\hline The control group & 50 & $44.73 \pm 10.86$ & 23 & 27 & - & - & & - \\
\hline CTD-ILD & 164 & $44.29 \pm 9.49$ & 76 & 88 & $1.96 \pm 2.77$ & $11(6.71 \%)$ & & $21.86 \pm 2.73$ \\
\hline ILD & 98 & $45.81 \pm 10.05$ & 42 & 56 & $2.15 \pm 2.08$ & $7(7.14 \%)$ & & $22.07 \pm 3.15$ \\
\hline
\end{tabular}

Table 2. Comparison of main symptoms of admitted patients ( $n, \%)$.

\begin{tabular}{llllll}
\hline Group & $\begin{array}{l}\text { Patients } \\
\text { number }\end{array}$ & Cough & $\begin{array}{l}\text { Short } \\
\text { breath }\end{array}$ & $\begin{array}{l}\text { Chest } \\
\text { pain }\end{array}$ & Dyspnea \\
\hline CTD-ILD & 164 & $123(75.0)$ & $119(72.56)$ & $47(28.66)$ & $52(31.71)$ \\
\hline ILD & 98 & $72(73.47)$ & $74(75.51)$ & $28(28.57)$ & $33(33.67)$ \\
\hline
\end{tabular}

Inclusive criteria: first, all patients were given chest HRCT within three days after admitted hospital; second, patients who met ILD criteria; third, patients or their families signed informed consent form.

Exclusive criteria: first, patients who cannot meet inclusive criteria above; second, patients accompanied with other blood system, alimentary system and malignant tumor; third, patients with emotional disorder; fourth, patients with poor compliance and so on.

\section{Instruments and reagents}

S3e flow cytometer was bought from Japanese Bio-Rad company; FITC-CD45, RD1-CD4, ECD-CD8 and PE-CD3 from American Beckman Kurt limited company; hemolysin Opti-Lyse No-Wash Lysing Solution from French Immunotech company.

\section{Observation indexes}

This study collected $2 \mathrm{ml}$ peripheral vein blood of all subjects, it put into EDTA anticoagulant tube. Then collecting $100 \mu \mathrm{l}$ anticoagulant blood into EP tube, $20 \mu \mathrm{l}$ same-type, ITC-CD45, RD1-CD4, ECD-CD8 and PE-CD3 fluorescently-labeled antibody were added, then blending. They were given incubation at $37^{\circ} \mathrm{C}$ without light for $10 \mathrm{~min}$, then adding $500 \mu \mathrm{l}$ hemolysin, blending, giving incubation at $37^{\circ} \mathrm{C}$ without light for $10 \mathrm{~min}$. $500 \mu \mathrm{l}$ PBS buffer solution was added, given centrifugation. Supernatant was discarded. $500 \mu \mathrm{l}$ PBS buffer solution was added, then blended, detected on computer laboratory.

\section{Statistical management}

This study used SPSS 21.0 statistical software to do t-test and $\chi^{2}$ test between two groups. Measurement data used t-test to do data comparison between two groups. Enumeration data $\chi^{2}$ test or Fisher's exact test. $\mathrm{P}<0.05$, there were statistical differences.

\section{Results}

\section{Comparison of CT iconography features of patients in two groups}

High resolution CT iconography examination results of patients in two groups show that manifestations of ground glass opacity, grid opacity, tractive bronchiectasia, consolidation opacity, pleural thickening or few pleural effusion are similar generally, there were no statistical differences $(\mathrm{P}<0.05$, Table 3$)$.

Table 3. Comparison of CT iconography features of patients in two groups (n, \%).

\begin{tabular}{|c|c|c|c|c|c|c|}
\hline Group & Patients number & Ground glass opacity & Grid opacity & Tractive bronchiectasia & Consolidation opacity & Pleural thickening \\
\hline CTD-ILD & 164 & $69(42.07)$ & $67(40.85)$ & $59(35.98)$ & $109(66.46)$ & $36(21.95)$ \\
\hline ILD & 98 & $35(35.71)$ & $46(46.94)$ & $28(28.57)$ & $71(72.45)$ & $17(17.35)$ \\
\hline
\end{tabular}

\section{Immune typing comparison of peripheral lymph cells of patients in two groups}

Compared with the normal control group and ILD group, $\mathrm{CD}^{+} \mathrm{CD}^{+} \mathrm{T}$ of patients in CTD-ILD increase obviously.
$\mathrm{CD} 3-\mathrm{CD} 56^{+}$cell number and $\mathrm{CD} 4^{+} / \mathrm{CD} 8^{+}$ratio decrease obviously, there were statistical differences $(\mathrm{P}<0.05)$. $\mathrm{T}$ cell of different types in peripheral blood of patients in ILD group 
Study of difference of peripheral blood lymphocytes immunophenotyping and NK cells on connective tissue disease combined with interstitial lung disease

compared with the control group, there were no statistical differences $(\mathrm{P}>0.05$, Table 4$)$.

Table 4. Immune typing comparison of peripheral lymph cells of patients in two groups $(\bar{x} \pm s)$.

\begin{tabular}{|c|c|c|c|c|c|c|}
\hline Group & $\mathrm{CD}^{+}$ & $\mathrm{CD}^{+}{ }^{+} \mathrm{CD}^{+}$ & $\mathrm{CD}^{+}{ }^{+} \mathrm{CD}^{+}$ & $\mathrm{CD}^{-\mathrm{CD}} 19^{+}$ & $\mathrm{CD}^{-\mathrm{CD}} 56^{+}$ & $\mathrm{CD4}^{+} / \mathrm{CD8}^{+}$ \\
\hline The control group & $64.27 \pm 4.91$ & $35.72 \pm 2.79$ & $24.45 \pm 3.17$ & $12.95 \pm 2.29$ & $16.24 \pm 3.78$ & $1.52 \pm 0.18$ \\
\hline CTD-ILD & $68.33 \pm 4.26$ & $36.03 \pm 3.14$ & $30.56 \pm 2.91^{a b}$ & $13.16 \pm 1.97$ & $10.69 \pm 5.26^{a b}$ & $1.19 \pm 0.22^{\mathrm{ab}}$ \\
\hline ILD & $66.82 \pm 6.37$ & $36.19 \pm 2.96$ & $25.82 \pm 3.40$ & $14.77 \pm 2.51$ & $14.73 \pm 4.35$ & $1.43 \pm 0.21$ \\
\hline
\end{tabular}

Note: ${ }^{\mathrm{a}}$ compared with the control group, $\mathrm{P}<0.05$; ${ }^{\mathrm{b}}$ compared with ILD group, $\mathrm{P}<0.05$.

\section{Discussion}

CTD is the common autoimmune system diseases in clinic at present, it mainly injuries connective tissue and vessels of whole body, such as ILD [9]. CTD-ILD occurs in female patients. This study selects 262 patients in respiratory department of our hospital randomly. The female patients accounts for $54.96 \%$. Since 70 s last century, CTD-ILD has attracted each nations widely gradually, but its mechanism is still unclear [10]. Because of different CTD primary disease, clinical manifestations of some patients have great differences, such as fever, arthralgia and skin injuries. But most patients will have obvious respiratory symptoms, including cough, short of breath, dyspnea and so on. The results of this study show that occurrence rate of respiratory system between CTDILD patients and ILD patients, there are no obvious statistical differences $(\mathrm{P}>0.05)$. In recent years, with the wide application of HRCT, diagnosis rate of ILD increase significantly. But whether it belongs to CTD-ILD still cannot make clear diagnosis. All ILD patients in this study are given HRCT examination. The results show that the manifestations of ground glass opacity, grid opacity, tractive bronchiectasia, consolidation opacity, pleural thickening or few pleural effusions are generally similar, there are statistical differences $(\mathrm{P}<0.05)$. It shows that only relying on clinical manifestations of ILD patients and HRCT results cannot judge onset caused by immune system disorder or infection. Because of rapid ILD development, some patients will have sudden respiratory failure, it is difficult to judge pathogenesis in clinic. Therefore, treatment methods selection is still the difficulty which disturbs clinical treatment all the time [11]. To rescue life of patients quickly, clinical doctors usually give great amount of glucocorticoid and anti-infection, which not only improve medical cost, also influences treatment effects, aggravate psychological burden of patients and their families [12]. Therefore, evaluation for immune state of ILD patients before treatment is vital important for selecting proper treatment methods.

This study explores pathogenesis of different ILD patients by comparing peripheral blood lymph cell typing of CTD-ILD patients, ILD patients and normal subjects. The study results show that, comparing with the normal control group and ILD group, $\mathrm{CD}^{+} \mathrm{CD} 8^{+} \mathrm{T}$ cells of patients in CTD-ILD group increase obviously. $\mathrm{CD} 4^{+} / \mathrm{CD}^{+}$decrease obviously, there are statistical differences $(\mathrm{P}<0.05)$. It shows $\mathrm{CD} 8^{+} \mathrm{T}$ as regulatory
$\mathrm{T}$ cell group with independent function, activated obviously to participate the immune injury of lung in active period of CTD. Mature $\mathrm{T}$ cells in peripheral blood of body are mainly CD3T cells. CD4T cells belong to assistant $\mathrm{T}$ cells. CD8T cells are mainly inhibited T cells and NK T cells. After activating CD3T cells and CD4T cells, which will participate cellular immune activity of body. Besides, CD3-CD19 ${ }^{+}$belongs to feature markers of B lymph cytomembrane, which reflects immune function of liquid in patients. $\mathrm{CD} 3^{+} \mathrm{CD} 8^{+}$level of CDT-ILD patients' increase. $\mathrm{CD}^{+} / \mathrm{CD}^{+}$ratio increase, it shows that cellular immune function of CTD-ILD patients is disorder. Proper immune intervention for patients may induce ideal treatment effects.

NK cells are the first defensive line of immune system of body, it only participates natural immune response, also can activate proliferation and activation of $\mathrm{T}$ lymph cells, participate acquired immune response by secreting multiple cellular factors $[13,14]$. CD56 is the typical molecular markers of NK surface [15]. Results of this study show that comparing with the normal control group and ILD group, CD3-CD56 $6^{+}$cells of patients in CTD-ILD group decrease obviously, there are statistical differences $(\mathrm{P}<0.05)$. Various $\mathrm{T}$ lymph cells of peripheral blood of patients in ILD group compared with the control group, there are no statistical differences $(\mathrm{P}<0.05)$. It shows immune state of CTD-ILD patients is abnormal furtherly. But for ILD patients, immune state is stable. It is uncertain to take the immune intervention. Examining pathogenesis furtherly, such as fungal infection, bacterial infection, viral infection and so on, so we can treat according to symptoms.

In conclusion, detecting changes of peripheral blood lymph immune typing and natural killer cells level of patients with ILD have significant clinical guidance for judging CTD and ILD whether have immune injury, and which will provide experimental basis for treatment methods selection in clinic.

\section{References}

1. Dickey BF, Whitsett JA. Understanding interstitial lung disease: It's in the mucus. Am J Respir Cell Mol Biol 2017; 57: 12-14.

2. Zhou MY. Analysis of clinical features of connective tissue disorder related interstitial lung disease. China Foreign Med Treat 2017; 42: 68-70. 
3. Zang LL. Study on application value of hihg-resolution CT in diagnosing infantile chronic pulmonary interstitium lesions. Contemp Med Forum 2017; 15: 136-137.

4. Jee AS, Adelstein S, Bleasel J. Role of autoantibodies in the diagnosis of connective-tissue disease ILD (CTD-ILD) and interstitial pneumonia with autoimmune features (IPAF). J Clin Med 2017; 6.

5. Adegunsoye A, Oldham JM, Valenzi E. Interstitial pneumonia with autoimmune features: value of histopathology. Arch Pathol Lab Med 2017; 141: 960-969.

6. Ren Y, Zhu P. The effects of inflammatory cells and cellular factors in inflammation and fibrosis of interstitial pulmonary diseases. Chinese J Cell Mol Immunol 2011; 27: 1272-1274.

7. Baldi BG, Carvalho CRR, Dias OM. Diffuse cystic lung diseases: differential diagnosis. J Bras Pneumol 2017; 43: 140-149.

8. Chinese Rheumatology Association of CMA. Diagnosis and treatment guide of CTD. Chinese J Rheumatol 2011; 15: $1-9$

9. Toyoda Y, Hanibuchi M, Kishi J. Clinical features and outcome of acute exacerbation of interstitial pneumonia associated with connective tissue disease. J Med Invest 2016; 63: 294-299.

10. Liang ZQ, Jiang FY, Zhao L. Clinical value of HRCT combined with pulmonary function examination in the diagnosis of connective tissue disease-related pulmonary interstitial lesions. Hebei Med 2017; 23: 594-597.

11. Hutloff A. T and B cell immune reactions in inflamed tissue. Z Rheumatol 2016; 75: 899-902.

12. Panchabhai TS, Farver C, Highland KB. Lymphocytic interstitial pneumonia. Clin Chest Med 2016; 37: 463-474.

13. Zhou YL, He CS. Diagnostic and treatment progress of IIM with ILD. Mod Med Health 2017; 33: 231-235.

14. Liu Y, Ma LX. Significance of anti-epithelial cell antibody and CTD with relevant lung diseases. J Clin Exp Med 2017; 16: 207-209.

15. Liu BB, Hou SP. The clinical analysis of peripheral blood lymphocyte immunophenotyping in interstitial lung lesions. Chinese J Lab Diag 2015; 19: 2066-2068.

\section{*Correspondence to}

Junli Wang

Department of Respiration

Shenzhen Hospital

Southern Medical University

PR China 